by means of models, patterns, \&c., are excellent as far as they go, but there seems to be great need of a systematic course specially designed to lead gradually up to the study of deductive geometry. The following books will be found useful by teachers who care to give the experimental method a trial: "Paper Folding," by T. Sundara Row (Addison and Co., Madras) ; "Inventional Gesmetry," hy W. G. Spencer (Williams and Norgate); "Experimental Geometry," hy Paul Bert (Cassell and Co.); "Nalural Geometry," by A. Mault (Macmillan and Co.); "Geometrical Drawing," by A. J. Pressland (Rivington, Percival, and Co.). To these may be added some older nnes, which $n$ ay occarionally be picked up second-hand : Scott Russell's "Geometry in Modern Life," Dupin's "Mathematics," and "Conversations on Geometry" (Anon.).

Adelaide Square, Bedford. EDward M. LANGLey.

\section{LILIENTHAL'S EXPERIMENTS IN FLYING.}

I $\mathrm{N}$ a previous article in NATURE (vol. xlix. p. 157) we had occasion to refer to the very interesting experiments which were being carried out by Herr Otto Lilienthal with regard to the possibility of human beings being able to acquire the art of flying through the air, more or less, in the fashion of birds.

These investigations in aerial navigation are conspicuous from all other attempts of the present day, by their great difference in the method of procedure adopted. The principle of Maxim's machine, for instance, is to construct an apparatus to navigate the air by itself, carrying one or more passengers. Every movement of the machine, however, is left to the apparatus itself, and to battle with the difficulty of sustaining its own equilibrium the mechanism must necessarily be most complicated.

Lilienthal depends for the success of his apparatus on himself, trusting to his powers of instinct to keep his equilibrium by corresponding movements of his centre of gravity. Man in this case is the main flyer, the apparatus being only an adjunct, and it is from the ability of the former that he expects to obtain positive results. His apparatus is simple, cheap, and easily constructed; these are great points, as experiments can be carried on, even at the expense of the loss of a few machines.

The whole success of aerial flying can be summed up in the word equalibrium, and it is here that the difficulty lies. Given a perfectly quiet or very nearly still air, there is no doubt that machines can be constructed so as to soar and travel through the air. This state of atmosphere is very rare; but, on the other hand, there are all sorts of disturbances, currents, and wave-motions which render aerial navigation a far greater difficulty than is usually imagined.

One often envies a bird which, with perfect ease, soars above us; but it must be recollected that it is endowed with a delicate system of nerves which are always on the alert, and answer to any call made on them to sustain equilibrium. These movements are made quite unconsclously, and with the loss of the minimum amount of energy. To construct an apparatus that would accomplish this in an efficient manner would be simply impossible; but there seems no reason why man should not approximate to it to a certain extent by the help of an appropriate framework. With perseverance and many trials be should be able to master at least some of the rudiments, and eventually make short flights.

For this reason Herr Lilienthal's experiments must be looked upon as yet only as first attempts, and consequently as experiments pure and simple, and experience only will show how far they can be successfully brought. Falls must be expected in the preliminary trials until the operator becomies accustomed to the many new conditions which make themselves apparent at every step, before they can be mastered instinctively. Similar difficulties have to be contended with when learn-

NO. I 312 , VOL. 51$]$ ing to ride a bicycle. The beginner is at first unable to keep his equilıbrium, and so wobbles here and there, with the loss of much power, until he eventually finds himself hugging the earth. This is simply because he is doing something unusual, and is not accustomed to the new conditions. An adept rider, on the other hand, never thinks of the possibility of falling, and quite unconsciously keeps his equilibrium without any exertion or

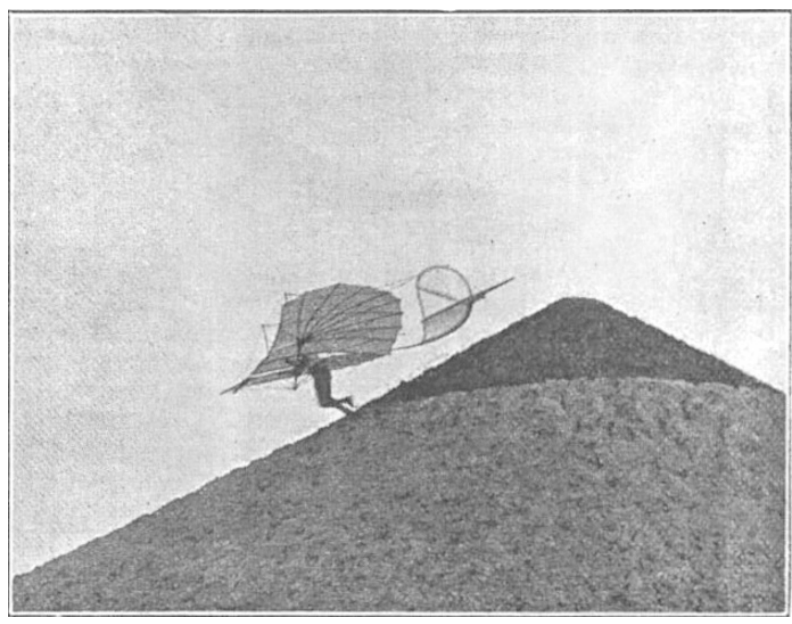

FIG. $x$.

loss of power on his part. So it is with this new sailing machine, and it is only by practice that success can be attained.

To commence operations the simplest apparatus must be used, and the easiest steps attempted. This is the way Herr Lilienthal began. In his first experiments, with the help of his wing-shaped framework, he made flights from elevated points in calm weather, the lengths

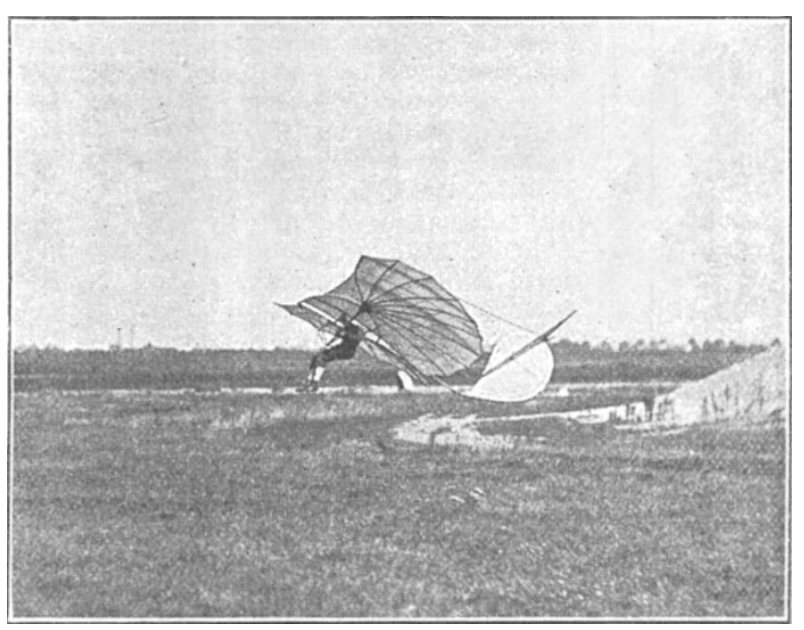

FIG. 2.

of these flights increasing as he gained in experience. Sometimes as many as 500 metres were covered in one bound under satisfactory conditions.

In his more recent experiments he has been making considerable progress in developing this mode of sailing. Two objects have been kept well in mind : the first, to accomplish that method of sailing which is adopted by birds which spend hours in the air at a time without ever 
flapping their wings; and second, to apply to his apparatus such dynamical means that will enable him, when sailing in a calm atmosphere, to prolong his flights.

To carry out these experiments he has thrown up, in

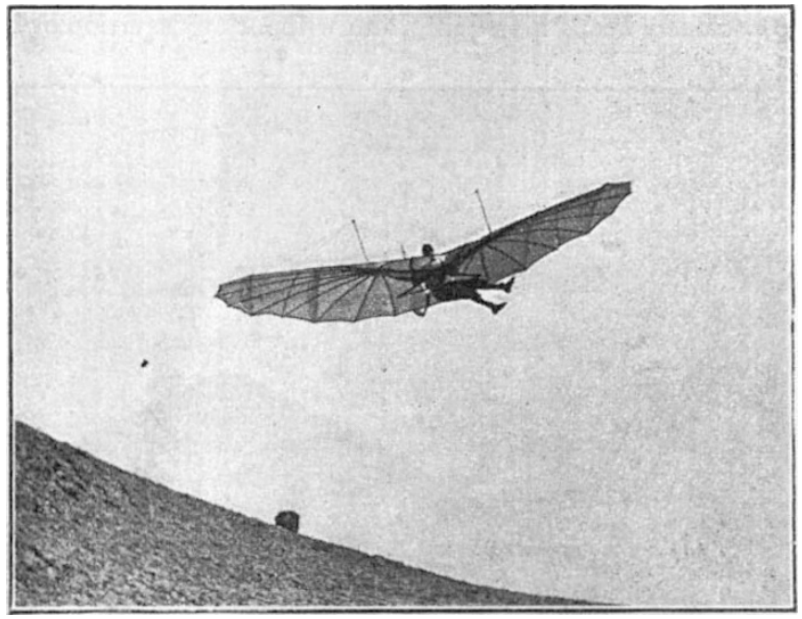

FIG. 3.

the neighbourhood of Berlin, a large conical mound, fifteen metres in height; this mound he uses as a starting-point for his flights. In Fig. I the operator is shown just commencing one of these flights. sails off until he alights again on the earth. Fig. 2 shows him just about to alight. It will be noticed that to come down easily and softly, he puts on the brake by offering to the air a greater expanse of wing, whereby his velocity is at once reduced.

By experience Herr Lilienthal has found that although in quiet weather he can manipulate his craft very easily, in windy weather the operator has to be more careful. The investigations in this direction have, however, been satisfactorily made, and he can now by an adroit movement of his body and that of the apparatus sustain his equilibrium, and sail successfully.

In his article on this subjert (Prometheus, No. 26I, p. 7), from which these references to his new experiments have been taken, he states that sometimes, when a strong wind was blowing, he has been surprised by sudden gusts, which, before he had time to make the necessary movements to sustain his equilibrium, had carried him high up in such a manner as to often take his breath away.

Fig. 3 illustrates the operator receiving such a sudden shock; it will be seen at once that to icontend with these new conditions he has had to bring his sail up to the direction of the blast, and to meet it if possible, while at the same time he has altered his whole centre of gravity by a movement of the lower part of his body.

Such movements as these cannot yet be made quite instantaneously, owing to lack of experience; but, as he justly remarks, with more practice he will no doubt be able to make them instinctively, just as the bicyclerider does.

To attain his second object, that is, to employ some mechanical aid to help him to sustain himself for longer intervals of time in the air, he has constructed a

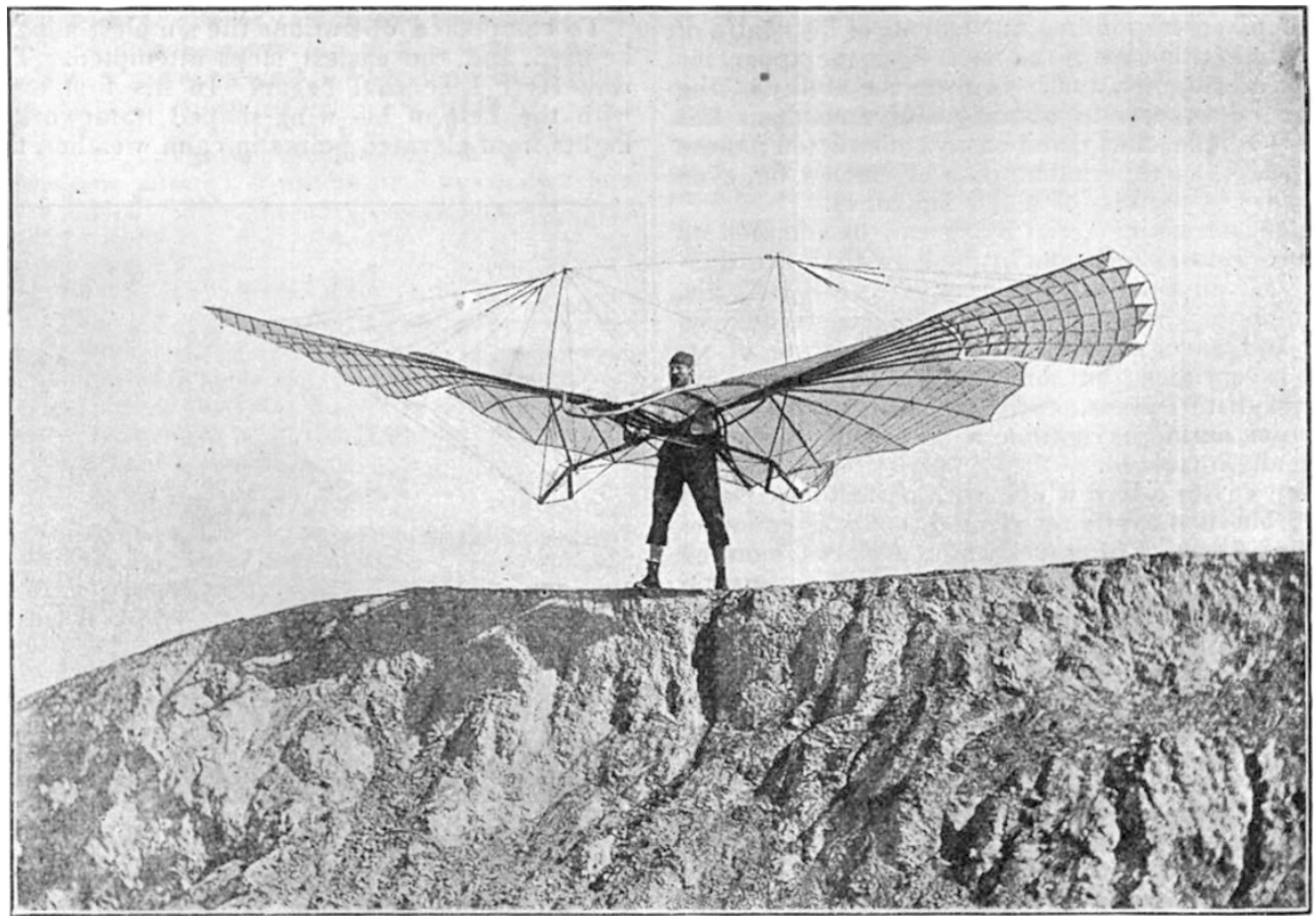

FiG, 4.

With a tight grip of the framework with his hands, he runs quickly down the slope until he has attained a sufficient velocity to raise him and his apparatus off the ground. When such conditions have been obtained, he new apparatus, somewhat, but not quite, similar to that up till now used. A good idea of this can be obtained from the accompanying illustration (Fig. 4).

A comparison of this flying machine with the sailins?

No. I 3 I 2 , VOL. $5 \mathrm{I}]$ 
machine in the previous figures will show that the extremities of the wings have been differently constructed, being composed at the ends of a series of feather-like sails. These latter are connected with a small machine, near the operator's body, which is driven by compressed carbonic acid gas; it is set in motion by a simple pressure of the finger. Such an addition has of course increased very considerably the weight and, therefore, the difficulty of handling the apparatus, and as yet it has only been used when the conditions were very suitable, as one serious fall would break up the machine.

Nevertheless the results up to now are very promising, and in calm weather Herr Lilienthal has been able to considerably prolong his flights. When, with the ordinary sailing machine, he would have come naturally down to the ground, he has found that an occasional flapping of these wings has helped to sustain him a longer time in the air, and to consequently cover greater distances.

Herr Lilienthal has shown now, that, with the simple sailing machine, flights can be made without any great risk. It would be good for the future progress of this mode of sailing if those interested in it, and who have the time and money, would take it up and pursue it further. What is wanted now is experience, and this can only be obtained by the co-operation of many workers.

\section{PETERS-DENZA-RANYARD.}

$A$ STRONOMICAL science has lost three of its votaries during the present month. Dr. C. F. W Peters died on December 2, and Father F. Denza, as well as Mr. A. C. Ranyard, passed away on Friday last.

Dr. Carl Friedrich Wilhelm Peters, Director of the Königsberg Observatory, died on December 2, after a protracted illness. He was born on April 16, 1844, at the Pulkowa Observatory, where his father, Prof. C. A. F. Peters, held an appointment under the Russian Government. In 1849 his father was appointed to the Chair of Astronomy at Königsberg, and in 1854 be was made Director of the Altona Observatory, which was afterwards transferred to Kiel. The son studied astronomy and mathematics at Berlin, Kiel, München, and Göltingen, and was placed on the staff of the Hamburg and Altona Observatories. Between I 869 and 1872 he made some valuable pendulum observations, chiefly for the Prussian Government. As Privatdocent at Kiel University he undertook a long series of chronometer tests for the German Navy, in the course of which he proved that they are influenced by changes of humidity as well as by changes of temperature. In 1880 , upon the death of his father, he edited the Astronomische Nachrichten for a year, after which he was appointed Extraordinary Professor at Kiel University. In 1883 he undertook the direction of the Naval Cbronometric Observatory at Kiel, whence he proceeded in 1888 to the directorship at Königsberg, where he terminated a useful and laborious career.

Father F. Denza died at Rome on the r 4 th inst. from cerebral hæmorrhage. He was well known to the scientific world by his works in astronomy, meteurology, and terrestrial magnetism, and at the time of his death was President of the Italian IIeteorological Society, and Director of the Observatory at Moncalieri, which he founded in 1859 , as well as of the Vatican Observatory, which was established by the Pope in I89I. It was owing to the untirıng energy of Father Denza that the Corrispondenza Meteorologica Italiana was established in connection with the Alpine Clubs, and that the results of observations at a large number of stations in the Alps and Apennines have been regularly published in the organ of the Italian Meteoro- logical Society. He was elected an honorary member of the Royal Meteorological Society in 1870 .

In astronomy his chief work relates to the observation of meteors. For several years he issued instructions to observers of meteors previous to every important shower, and he published numerous tables and papers on the observations carried on under his guidance, both in Comptesrendus and the Monthly Notices of the Royal Astronomical Society. When the Directorship of the Vatican Observatory was taken by Father Denza a very comprehensive programme was drawn up, embracing investigations in meteorology, terrestrial magnetism geodynamics, and astronomy. Observations in each of these branches of knowledge have increased in number every year since then, and the fourth volume of the Pubblicazioni of the Observatory, received by us on the same day as the news of Father Denza's death, is even greater in bulk than any of the previous ones. Father Denza was chiefly instrumental in making the Vatican Observatory one of those co-operating in the production of the photographic star-chart. He devoted his best energies to the advancement of the scheme, and to the progress of astronomical photography. The reports to which reference has been made, contain evidence of his knowledge of what had been done in other astronomical observatories, and of his ability to direct and further the advancement of celestial photography. $H_{\text {is }}$ services to astronomy have earned for him an honoured place in our memory of the sons of science.

Mr. Ranyard was born in 1845 . He was educated at Cambridge University, and was called to the Bar in $187 \mathrm{r}$. He was one of the founders of the London Mathematical Society, of which he was originally joint secretary with Mr. George De Morgan, Prof, Augustus De Morgan being president. He became a Fellow of the Royal Astronomical Society in 1864 . In 1870 he was assistant secretary of a joint committee of the Royal Society and the Astronomical Society, which organised the expedition despatched to Sicily, Spain, and Oran to observe the total solar eclipse of December $2 \mathrm{I}$. On his return to England he undertook to assist Sir G. B. Airy in the preparation of the report of the observations of the total eclipses both of 1870 and 1860 . Ultimately Sir George Airy transferred the work entirely to Mr. Ranyard, and in 1880 the report was published by the Royal Astronomical Society as vol xli. of its "Memoirs." He observed the total eclipse of July 29, I 878 , from Cherry Creek, near Denver, Colorado, and the total eclipse of May, I882, from Sohag, in Upper Egypt. In addition to papers on the corona and matters connected with physical astronomy, he also publıshed papers on the "Early History of the Achromatic Telescope," and on "Photographic Action." In conjunction with Lord Crawford and Balcarres, he undertook in 1872 a series of experiments on photographic irradiation; and in 1886 he demonstrated by a series of experiments that the intensity of photographic action varies directly as the brightness of the object photographed, and directly as the time of the exposure. The "uld and New Astronomy," designed by Mr. Proctor, was cumpleted in I 892 by $\mathrm{Mr}$. Ranyard, who contributed to it some very important sections on the structure of the stellar universe.

\section{NOTES.}

THE newly-discovered gas is to be the subject of a discussion at a meeting of the Royal Society on January $3 \mathrm{I}$, when Lord Rayleigh and Prof. Ramsay will present their paper. This will be the first meeting under a resolution of the Council of the Society passed last session, whereby certain ueetıngs, not more than four in number, are to be devoted every year, each to the hearing and consideration of some one important communication, or to the discussion of some important topic.

NO. $13[2$, VOL. 5 I] 